Article

\title{
Cross-Country Comparison of Hourly Electricity Mixes for EV Charging Profiles
}

\author{
Michel Noussan ${ }^{1, *(1)}$ and Francesco Neirotti ${ }^{2}$ (i) \\ 1 Future Energy Program, Fondazione Eni Enrico Mattei, Corso Magenta 63, 20123 Milano, Italy \\ 2 Department of Energy, Politecnico di Torino, Corso Duca degli Abruzzi 24, 10129 Torino, Italy; \\ francesco.neirotti@polito.it \\ * Correspondence: michel.noussan@feem.it
}

Received: 9 April 2020; Accepted: 14 May 2020; Published: 16 May 2020 updates

\begin{abstract}
Electric vehicles, when coupled to electricity generation from renewable energy sources, can become a viable solution to decarbonize the transport sector. However, given the high variability of electricity mixes on a daily and seasonal basis, high-resolution profiles are needed for a precise analysis of the impacts of electric vehicles in terms of greenhouse gases emissions. This paper presents a comparison of different charging profiles evaluated on 10 European countries over four years, to highlight the effects of national electricity mixes and of the type of charging location on the specific emissions of EVs charging. This study, based on three archetypal charging profiles, provide a quantification of the potential influence of different charging strategies on the average emission factor of the electricity supplied to electric vehicles. The results show that the variability related to charging profiles is generally limited, with an average variation range of $6 \%$ for any given country and year, while in several countries the variability from one year to another is much larger, with an average range of $18 \%$ for any given country and charging profile.
\end{abstract}

Keywords: electric vehicles; electricity mix; charging profile; emissions; energy

\section{Introduction}

Electrification of final sectors is among the main studied solution to mitigate the climate-change related issues together with the pollutant emissions in urban environments. In fact, the electricity sector is experiencing a steep growth rate in final energy consumption, and its renewable share is increasing [1]. At the same time, renewable energy sources (RESs) stress the stability and balance of the grid, due to their unpredictable and variable production.

The transport sector is among those that could see a significant increase of electricity penetration, increasing its RES use [2] and helping the grid balancing [3]. Moreover, electrification of transport leads to significant benefits related to the decrease of some pollutants in cities. These factors are giving an important boost to the electric vehible (EV) market [4], to radically convert the environmental impact of the transport sector [5] and their interaction with new technologies [6,7].

Electric vehicles (EVs) are not new technology, since they first appeared during the nineteenth century, but they were overcome by internal combustion engines thanks to their better reliability and available range. Moreover, in 1908 Henry Ford spread the gasoline engine vehicles around the globe with his affordable and revolutionary Ford Model T [8], putting an end to the EV market. Today, thanks to the new conditions discussed above, there are around 5 million electric cars running on the roads, marking a $+40 \%$ increase with respect to the 3 million of 2018, with China as leading market [9], followed by the United States and the northern EU regions [10], confirming the current evolution trend towards the electric mobility. The global COVID-19 crisis of early 2020, together with the current low 
oil prices, is having a short-term impact on this positive trend, but the medium- and long-term effects are not yet clear.

Due to the increasing amount of electrical energy derived from fluctuating resources, the timing of electricity demand is getting high importance to fully exploit the electrification benefit potential, since production and consumption profiles show large variations on a daily, weekly and seasonal basis. This oscillating behaviours lead to significant variations of the actual energy mix during even in small time windows, with consequent variability of the main energy indicators used to assess the impact of final energy sectors, such as the Primary Energy Factor (PEF) or the $\mathrm{CO}_{2}$ emission factor (EF) [11].

Accurate temporal analyses have been carried on in different works [12,13]. In [12], the authors present the discrepancy between the annual energy mix, which is often used as reference, and the real energy mix of the actual consumption of different heat pumps based on hourly calculations. In [13], the temporal changes in electricity conversion factors supporting a life cycle assessment (LCA) are evaluated, underling the importance of dynamic conversion factors to correctly estimated the entire life cycle impact of a process. Fluctuating RESs are also producing undesired effects related to grid stability. Transport electrification has been pinpointed as a possible solution to reduce the stress and improve the grid reliability [14], especially at the distribution level. A smart integration and management of the charging strategies could bring important benefits for the network operators. At the same tame, unplanned and uncontrolled management of future EVs charging may produce severe impacts over the electric network in terms of efficiency and reliability [15].

In order to properly forecast the impact on the grid, both in terms of RES electricity usage and grid stability issues, detailed analyses based on different charging profiles are needed. Since EV adoption is still at an early stage, there is a small amount of real profiles freely available [16], and they are generally limited to specific conditions (e.g., private fleets, limited geographical coverage, single user type, etc.). Thus, large part of modelling and simulation studies has been performed with artificial charging profiles created making different assumptions or using stochastic and mathematical techniques. In [17], a two-step modelling framework extracts information from a small amount of real data, in order to create reliable charging profiles to asses the potential impact on the grid. Similarly, $[18,19]$ use stochastic simulations to generate realistic profiles based on real data collection. In particular, in [19] the authors underline the difference between the week and week-end consumption patterns, and they stress the importance of a stochastic approach to effectively manage the EV charging periods. This last finding is supported also in [20], where a data-driven machine-learning algorithm is used to replicate historical loads pattern and effectively manage the power system to avoid disservice. Schauble et al. [21] deeply investigated three large datasets in order to underline the large information hidden in charging patterns data, with the aim of spotlighting the most important ones to be used to create reliable profiles. The resulting load profiles are in line with other scientific works. Nevertheless, validation and generalization of the resulting profiles are reported as difficult tasks to be performed due to the wide differences between the analysed data and the observed fleets. Instead, in [22], a user behaviour simulation is used to test potential price incentives. The results highlight that variable pricing can be used to modify the user behaviour and so the charging profiles allowing for a more secure profile forecasting.

While much attention has been paid to charging profiles variation related to grid stability, a comprehensive assessment of the impact on greenhouse gas (GHG) emissions on multiple countries is still lacking. In this paper, we evaluate this impact by considering detailed temporal analyses for both electricity generation and EVs' charging profiles. The EVs' electrical consumption, based on three main charging archetypes, will be compared with several national energy production mixes on an hourly basis, to evaluate the differences between the average annual energy mix and the actual EV consumption patterns. In order to forecast the potential benefit of transport electrification, different countries with specific production portfolios have been considered (Austria, France, Germany, Switzerland, Italy, Netherlands, United Kingdom, Ireland, Denmark, Poland). 


\section{Methods}

The high-resolution analysis of the GHG emissions related to the electricity supplied to EVs requires multiple steps. Different charging profiles and electricity generation mixes are considered and compared, to calculate the weighted average of the hourly emission factors based on different generation technologies. This section presents a description of the methods and the hypotheses that have been used.

\subsection{EVs' Charging Profiles}

The charging profiles considered in this study have been chosen with the aim of comparing archetypal profiles related to EV charging in three different locations: at home, at work and in public charging stations (usually associated with different services, such as restaurants, shopping centers, cinemas, etc.). The profiles are the result of an analysis based on several data from real charging profiles in Germany, based on a complex model that considered different car segments, households characteristics and charging behaviours, to build up representative profiles for home, work and public charging [23]. The profiles are based on an available power of $3.7 \mathrm{~kW}$ for home and work chargers, and $22 \mathrm{~kW}$ for public charging points.

The profiles have been normalized on the total demand of a weekday for each type of charging, to analyze comparable results considering the same amount of energy supplied to a vehicle. Figure 1 represents the three different profiles compared for a weekday and a weekend, measuring the contribution of each hour of the day on the total charging over a weekday. An alternative approach may have been the analysis of a large number of real-world EV charging profiles, which may be collected by charging station companies or EV fleet owners. Unfortunately, the availability of statistically significant datasets for research purposes remains limited, and they are often limited in terms of charging locations, temporal spanning and country spanning, which may result in a limited variability. For this reason, this work has been performed on standard profiles defined from literature studies, but future developments of this work may assess the effect of considering real data on the results.

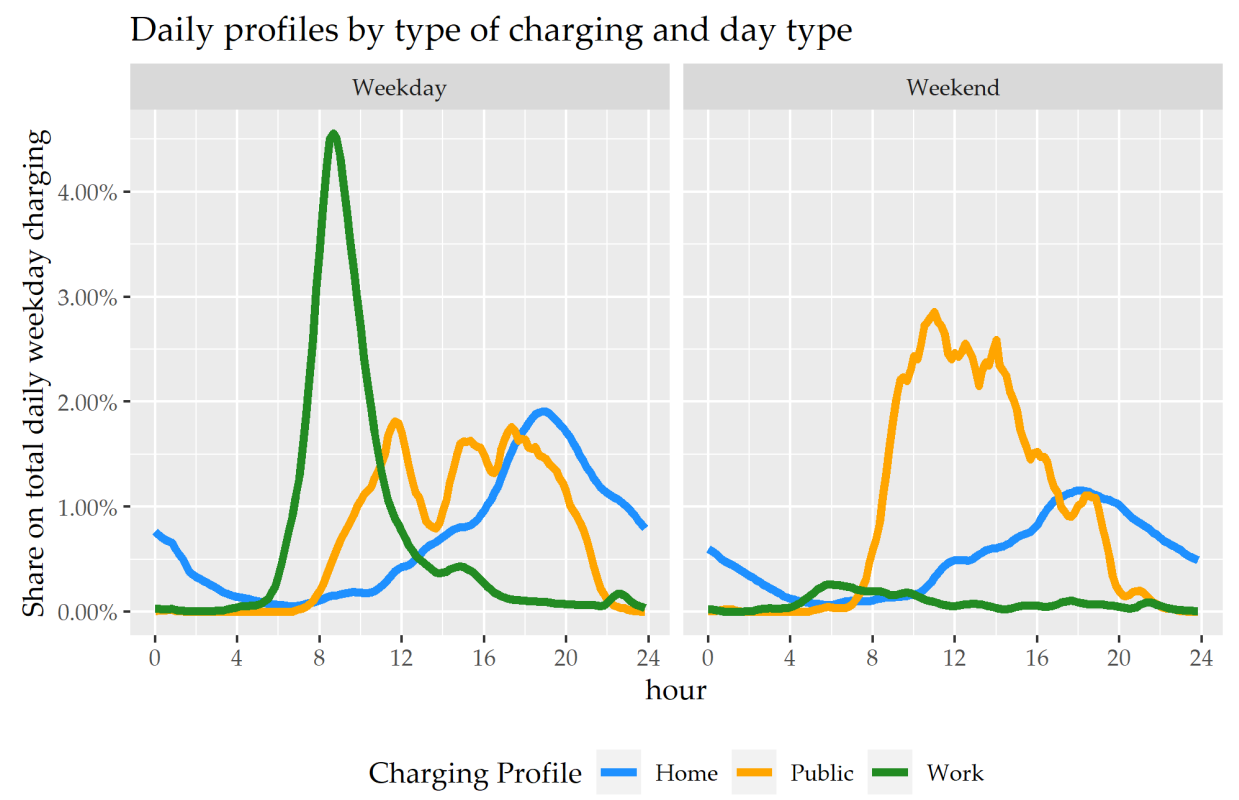

Figure 1. Different electric vehicle (EV) charging profiles.

Another potential limitation lies in the fact that the considered profiles are representative for Germany and may differ from a country to another. Again, this approximation is in part related to the unavailability of a large set of data over different countries, especially considering the limited 
penetration of EVs. Nevertheless, we believe that the assumptions on which these charging behaviours have been build can still be an acceptable representation for the European countries that are being considered in this study.

All the results are presented in relative terms, considering the electricity mixes that lead to specific emission factors for the electricity supplied to EVs, differentiated per each country and type of profile. The resulting emission factors may be used to quantify the impact of the electricity supply to different EVs, with a greater accuracy in comparison with the common practice of considering average annual performance indicators.

\subsection{Electricity Generation Mixes}

Together with EV charging profiles, the quantification of actual emission factors requires also high-resolution electricity generation mixes, which have been calculated for several countries. The methodology is described below.

\subsubsection{Data Sources}

The power generation data per each country has been retrieved from the European Network Transmission Operators for Electricity (ENTSOE) Transparency Platform [24], which makes production data freely available for most European countries. The ENTSOE platform groups together 43 transmission system operators (TSOs) from 36 countries (complete list available at [25]). The main objective of the ENTSOE project is to ensure an optimal functioning of the electricity market as well as support the implementation of the ambitious EU targets on renewable energy and climate change policies [26,27]. Finally, it represents the largest open EU dataset on electricity, including generation data, actual load data and production forecasts for some sources. For some countries, the geographical detail is even higher, with some information available at the level of the different bidding zones, which vary from a country to another.

The analysis performed in this research work has been limited to the generation profiles and electricity mixes at the country level, without taking into account the additional information related to import/export data. To increase the accuracy of the estimation, a deeper investigation of traded electricity may lead to slightly different results. However, to obtain meaningful results it would be necessary to consider all the countries that have international power trading, and in some cases not all the necessary data are available.

\subsubsection{Data Processing}

We took 10 European countries into account in this work, namely: Austria, Denmark, France, Germany, Ireland, Italy, Netherlands, Poland, Switzerland and the United Kingdom. The generation data were available with 60,30 and 15 min timestamps, depending on the country. The wide variety of the energy production portfolio of these regions will highlight the effect of $\mathrm{EV}$ profiles in very different electricity production mixes. The power generation by source was collected for the years 2016 to 2019 in order to highlight the differences that may occur among the years, thus considering the variability of the generation mix within each country. The data presented a large number of energy sources (hard coal, brown coal, wind on/off-shore, etc.) but in order to get meaningful electricity mixes to be compared among the different countries they were aggregated into 11 main sources: biomass, coal, geothermal, hydro, natural gas, nuclear, oil, solar, waste, wind and other.

The dataset presented a certain amount of "NA" data, both representing missing values as well as the lack of a specific generation technology in any specific country (e.g., Nuclear power in Italy or Denmark is always represented by NA values). Since no detailed information was reported for all the considered countries, all the NA were replaced with zeroes, being aware of the potential under-estimation that can arise from this simplification.

The data were elaborated to build an hourly dataset by calculating the hourly average power for each source in each country, to perform a comparable analysis across all the available countries. 
Moreover, the hourly share per energy source Share $_{i, h}$ was calculated as the ratio between the energy produced by a specific source $i$ and the total energy produced in the considered hourly time interval $E_{t o t, h}$ :

$$
\text { Share }_{i, h}=\frac{\sum_{i} E_{i, h}}{E_{t o t, h}}
$$

The hourly shares are used to calculate the emission factors described in the following sections.

A general comparison of the electricity mixes in different countries is reported in Figure 2, where the average values for the year 2019 are reported for each country. The RES category includes solar, hydro, wind, biomass and geothermal, while the fossil one includes coal, gas, oil and other. Electricity generation from waste is allocated in equal parts to fossil and RESs, in accordance to statistical rules that are applied in some countries, to account for the biological share of municipal solid waste.

The chart shows the considerable variability of electricity mixes across countries, which in turn could lead to significant differences in the emissions related to EV charging. While only 2019 is represented in the chart, additional differences arise from one year to the other, as will be better discussed in the following sections. It has also to be noted that the categories fossil and RES include different sources that have a broad range of specific emission factors as well as other characteristics (e.g., availability, predictability, dispatchability etc.).

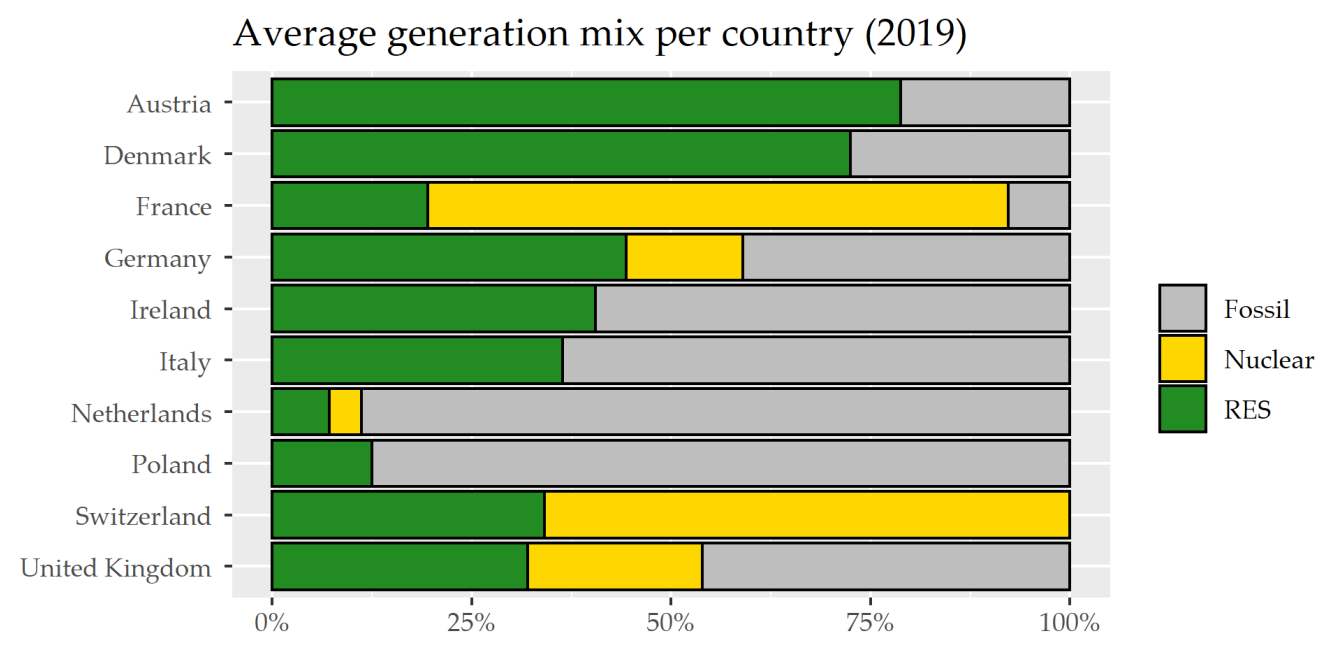

Figure 2. Average electricity mixes in 2019 on an annual basis in different European countries.

\subsubsection{Data Quality Issues}

ENTSOE dataset is the largest and most comprehensive source of data about the European electricity market, but data quality has been criticized due to lack of completeness and consistency $[28,29]$.

The EU report [29] is focusing on four main issues: data completeness, accuracy, timeliness and user-friendliness. A detailed analysis is carried on based on online surveys with users, interviews with experts, statistical analyses of the data in 2015/2016 and other documents in the literature. The main outcomes are that the generation and load data present inconsistency and missing values with poor documentation about the reasons ad the origin of these gaps. As an example, in the Aggregated Generation per Type data the "Other" category is abused. Natural Gas Combined Cycle (NGCC) plants are aggregated in "Other" instead of "Natural Gas", probably due to the efficiency difference with the usual gas plants as also highlighted in [30]. Moreover, this choice was not explicitly documented in the dataset, but has been discovered by the authors of [30] only after a specific inquiry. This choice, of course, can lead to major errors when computing the emission factor (EF) or the primary energy factor (PEF) of different countries in which this kind of plants have a significant share of 
electricity generation (e.g., Italy). For this reason, in our work the parameters related to this category have been mostly related to NGCC plants.

Nevertheless, a data quality improvement has been highlighted over the years, especially in 2018 and 2019, and different countries present coherent data with official national data [29]. Finally, it is worth to mention that ENTSOE developed and maintains the platform and the database, but it is not directly responsible for the quality of the data. The data providers are the National transmission system operators (TSOs), sometimes supported by other organizations which, after a proper intermediate service for data cleaning and organization, submit the electricity data. Sometimes the TSO does not have direct access to very small plants data or do not take into account the back-up plants (the ones that are turned on just in specific cases) leading to the underestimation of the generation from specific sources [30]. This is a problem especially for distributed solar plants, whose generation may not be correctly represented in ENTSOE data, since each country has different methods and categories to evaluate and quantify the energy generation from final users.

\subsection{Emission Factors}

Hourly emission factors for electricity were calculated on the basis of the actual electricity mix of power generation in each country, as described in the previous section, for the years 2016-2019 considered in this analysis. The analysis is limited to domestic generation in the country, since the calculation of the share of imported electricity would have considerably complicated the analysis, with limited additional benefits. Moreover, it would have been necessary to consider other countries for which not all the required data were available.

The hourly emission factors $e f_{h}$ were calculated as a weighted average of the electricity generation by different sources, in accordance with the following equation:

$$
e f_{h}=\frac{\sum_{i} e f_{i} * E_{h, i}}{E_{h}}
$$

where $e f_{i}$ are the electricity emission factors for the different energy sources, and $E_{h, i}$ is the hourly electricity production from each source and $E_{h}$ is the total electricity generated in this hour.

Emission factors have been calculated by taking into account direct emissions as well as LCA emissions, based on specific average coefficients available in the literature, reported in Table 1. The LCA data have been chosen from international standards, by considering the values provided by IPCC [31], which is the leading reference for emission factors. A different approach has been chosen for the direct emissions, since data have been obtained by real calculations for the Italian power plants in operation in 2019 [32]. We believe that this approach reflects better the operational conditions of power plants in European countries, although the availability of differentiated coefficients for each country would further improve our results. The emissions factors include the contribution of $\mathrm{CO}_{2}, \mathrm{~N}_{2} \mathrm{O}$ and $\mathrm{CH}_{4}$, and they are expressed in $\mathrm{g}_{\mathrm{CO} 2 \mathrm{eq}} / \mathrm{kWh}$.

An approximation is introduced by choosing average emissions factors by energy source, which may be variable both across countries and across and within years. Considering any energy source, but especially fossil fuels, the electricity emission factor is related to the conversion efficiency of the plant, which shows variations related to the technology, the size of the plants, the outdoor temperature and other design and operational parameters. Moreover, in combined heat and power (CHP) plants the emissions may be allocated properly considering both heat and electricity [33], and multiple methods are available based on different parameters.

Thus, a more precise approach would require to calculate the actual efficiency of each power plant in each given hour, based on a number of data on fuel consumption and heat production that are unfortunately not available over such a wide range of countries and with the required high temporal detail. Still, we believe that using annual average data from real plants represents a better estimation than considering nominal values from power plants design parameters. A future research work 
focused on a single country may provide additional information on the potential variability related to annual operations and CHP allocation methods.

Table 1. Emission factors for electricity generation from different sources [31,32].

\begin{tabular}{lcc}
\hline$g_{\text {CO2eq }} / \mathbf{k W h} \boldsymbol{e l}$ & Direct Emissions & LCA Emissions \\
\hline Biomass & 0 & 230 \\
Coal & 870 & 910 \\
Gas & 368 & 490 \\
Geothermal & 0 & 38 \\
Hydro & 0 & 24 \\
Nuclear & 0 & 12 \\
Oil & 545 & 650 \\
Other & 368 & 490 \\
Solar & 0 & 45 \\
Waste & 555 & 620 \\
Wind & 0 & 11 \\
\hline
\end{tabular}

\section{Results and Discussion}

\subsection{Calculation of Hourly Emission Factors}

The first step of the analysis led to the calculation of hourly emission factors, which show significant ranges of variation, as reported in Figure 3 for direct emissions. With the exception of Switzerland, which was totally relying on RES (mostly hydro) and nuclear energy, the other countries showed a very large range of emission factors that was the result of seasonal and daily variations in their electricity mixes. These results underline the importance of performing a more detailed assessment considering actual EV charging profiles rather than considering simple average annual emission factors.

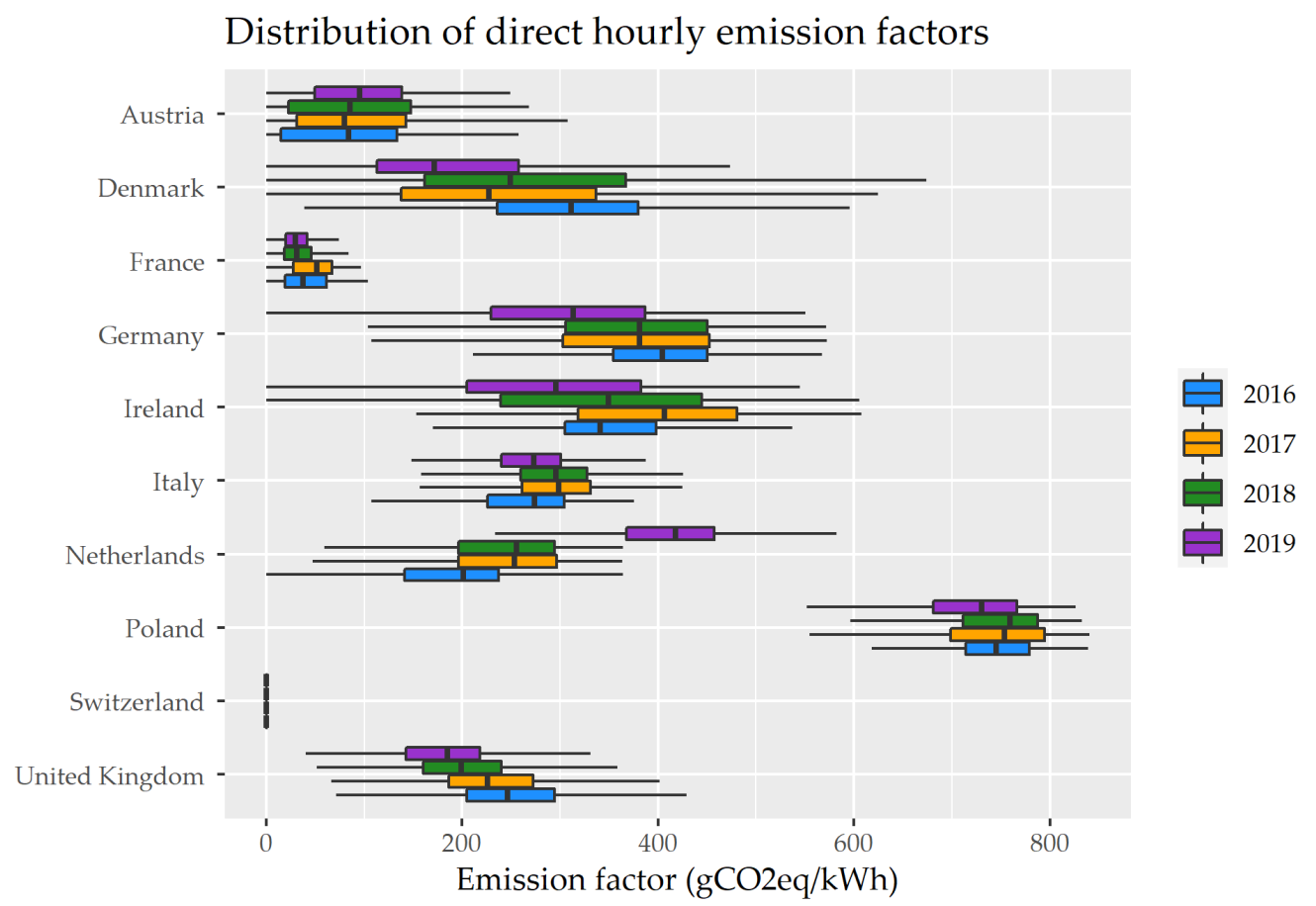

Figure 3. Comparison of direct hourly emission factors in selected European countries.

This variability also emerged while considering the daily patterns of the hourly emission factors of the electricity generation, as reported in Figure 4. Considering some random working days 
(e.g., the second Wednesday for selected months in 2019) it is clear that the generation mix in each day showed a different behaviour for each country, which was related to multiple factors. The calculation of an annual emission factor starting from hourly resolution allowed us to take into account this variability, but at the same time provided a single indicator that quantified the combined effect of this variability when considering an entire year.

It is important to remember that some results may be affected of the quality of the available data that has been discussed in the previous sections, especially for 2016.

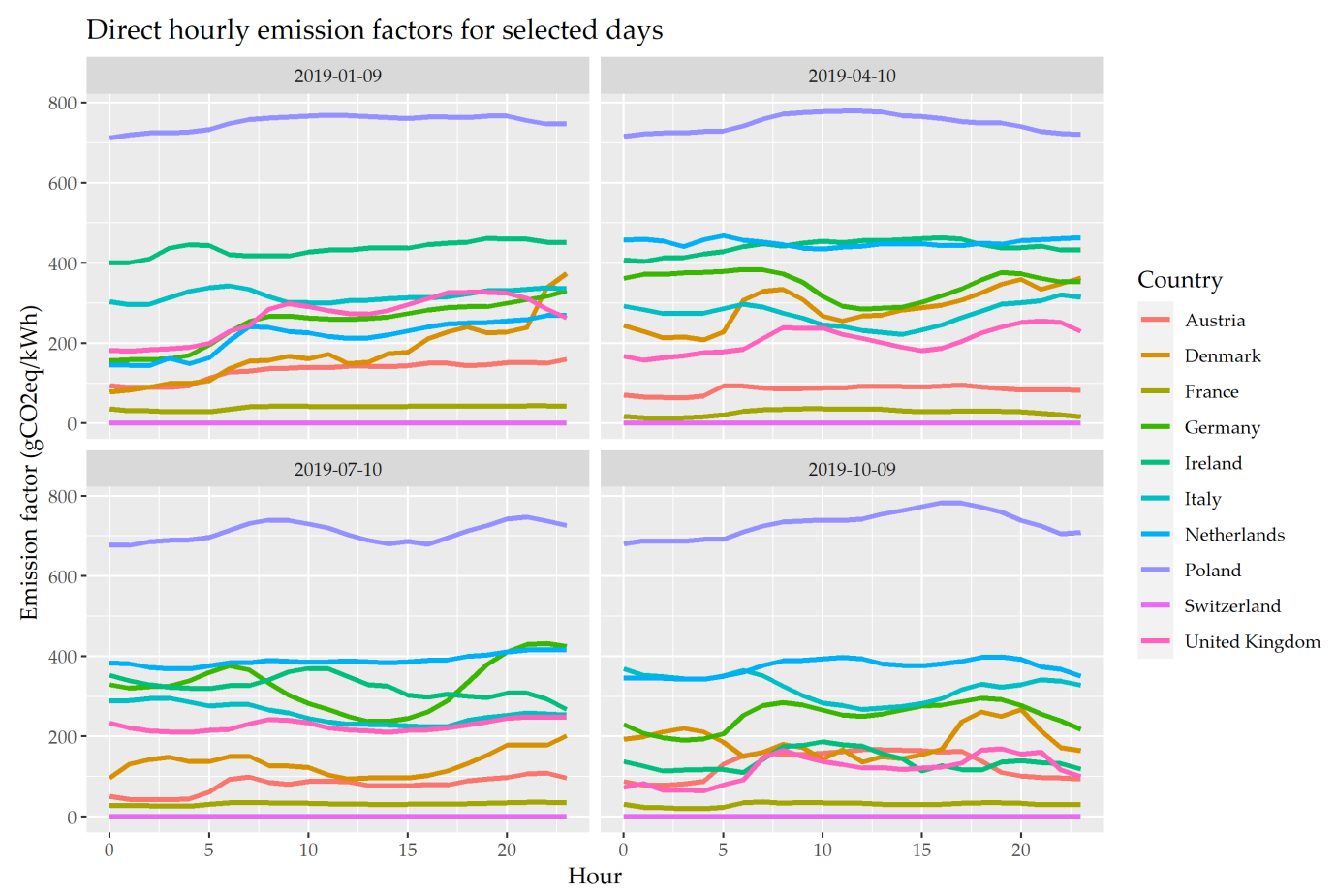

Figure 4. Comparison of direct hourly emission factors for selected days (the second Wednesday of different months in 2019.)

\subsection{Variability of Emission Factors}

As described above, annual emission factors for the electricity supplied to EVs have been calculated for each country considering three different EV charging profiles, and evaluating them in four different years. The combined results, highlighting the variability of direct and LCA emission factors for each country, are showed in Figure 5. A summary of the main information related to the range of variation for each country is also reported in Table 2.

While in some countries the variations remain under 10\% (in Switzerland, Poland and Italy), in other cases the maximum variation from the mean can reach values higher than $20 \%$, due to the combined effect of different charging profiles on the demand side as well as different electricity generation mixes on the supply side. Considering all the combinations, the increase of emissions when considering the LCA perspective is on average around $56 \mathrm{~g} / \mathrm{kWh}$ (with variations in the range $15-97 \mathrm{~g} / \mathrm{kWh}$ ), which represents a $30 \%$ increase of the direct emissions. Still, with the exception of Switzerland, which totally relies on nuclear and hydropower, the largest share of GHG emissions in the other countries is related to direct emissions from power plants. 


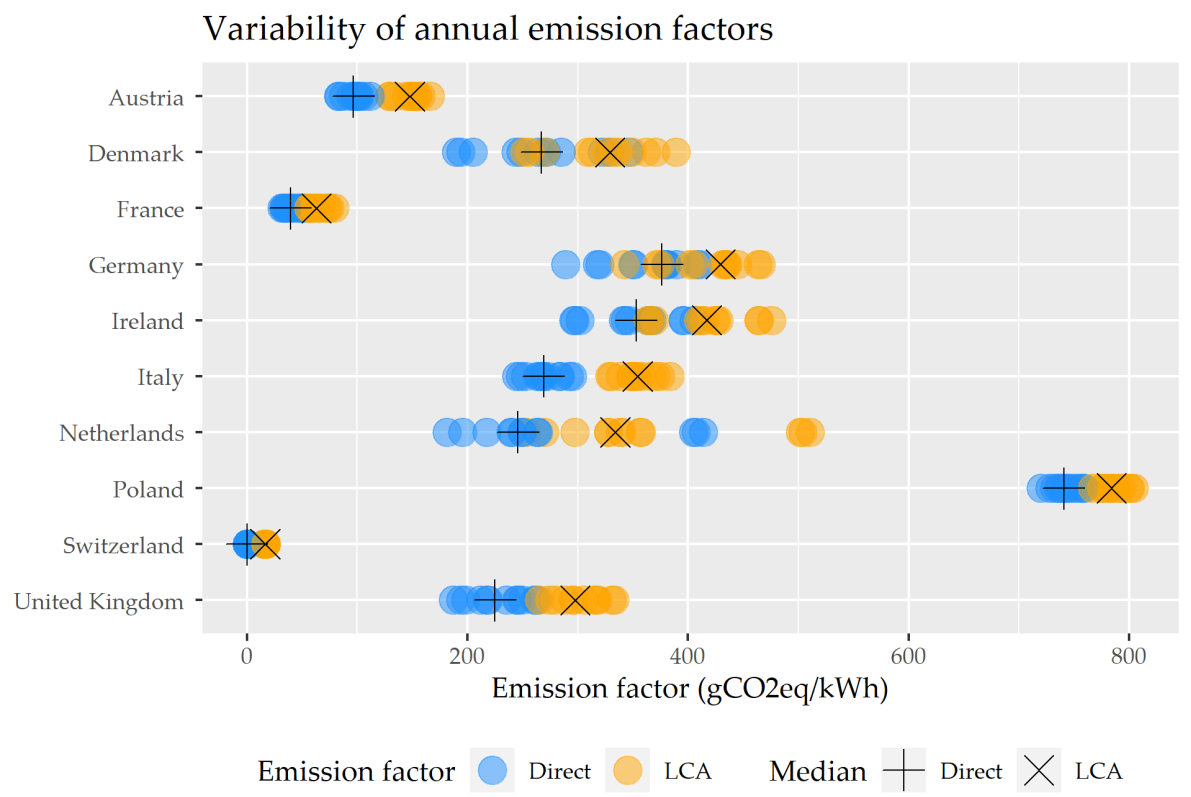

Figure 5. Variability of annual emission factors of EV charging in each country (with variable year and charging profile).

Table 2. Variation of annual emission factors over charging profile and years for each country

\begin{tabular}{lrrrrrrrr}
\hline$g_{\text {CO2eq }} / k_{W h}$ l & \multicolumn{4}{c}{ Direct Emission Factor } & \multicolumn{3}{c}{ LCA Emission Factor } \\
\hline & Mean & \multicolumn{1}{c}{ Min } & Max & Range vs. Mean & Mean & Min & Max & Range vs. Mean \\
\hline Austria & 96.9 & 83.1 & 111.4 & $-14 \% / 15 \%$ & 147.5 & 129.1 & 166.2 & $-13 \% / 13 \%$ \\
Denmark & 264.0 & 189.7 & 346.4 & $-28 \% / 31 \%$ & 332.4 & 251.8 & 389.0 & $-22 \% / 21 \%$ \\
France & 41.0 & 31.6 & 54.0 & $-23 \% / 32 \%$ & 65.2 & 55.8 & 79.8 & $-14 \% / 22 \%$ \\
Germany & 363.1 & 288.7 & 410.6 & $-20 \% / 13 \%$ & 417.1 & 342.1 & 466.3 & $-18 \% / 12 \%$ \\
Ireland & 351.6 & 296.5 & 405.5 & $-16 \% / 15 \%$ & 418.0 & 363.6 & 475.8 & $-13 \% / 14 \%$ \\
Italy & 269.7 & 244.7 & 295.1 & $-9 \% / 9 \%$ & 354.5 & 329.0 & 383.7 & $-7 \% / 8 \%$ \\
Netherlands & 277.1 & 181.6 & 413.6 & $-34 \% / 49 \%$ & 365.3 & 253.7 & 510.5 & $-31 \% / 40 \%$ \\
Poland & 742.2 & 720.2 & 759.2 & $-3 \% / 2 \%$ & 786.6 & 766.8 & 804.7 & $-3 \% / 2 \%$ \\
Switzerland & 0.0 & 0.0 & 0.0 & -16.7 & 15.5 & 17.4 & $-7 \% / 4 \%$ \\
United Kingdom & 227.2 & 186.8 & 263.1 & $-18 \% / 16 \%$ & 301.7 & 265.4 & 333.2 & $-12 \% / 10 \%$ \\
\hline
\end{tabular}

While the variation of the emission factors for electricity from a country to another has been widely discussed in the literature, these results point out that significant variations also existed when considering the variations within a single country, due to a combined effect of different electricity mixes over the years and for different profiles. The problems related to the quality of data discussed above may also have an impact on the highest variability ranges, and the availability of better data in the next years may help in isolating this potential effect.

Moreover, Figure 6 illustrates an additional seasonal variability related to the monthly emission factors, that have been calculated for each month, year and country. This chart illustrates the fact that the very same charging profiles had different impacts depending on the period of the year that was considered. While in some cases there might be some variations related to the car usage over the year (e.g., vacation periods, different leisure activities, etc.), in general it can be assumed that private car use remains relatively constant over the year. For this reason, the main results of our work were considered on an annual basis rather than on a monthly basis. 


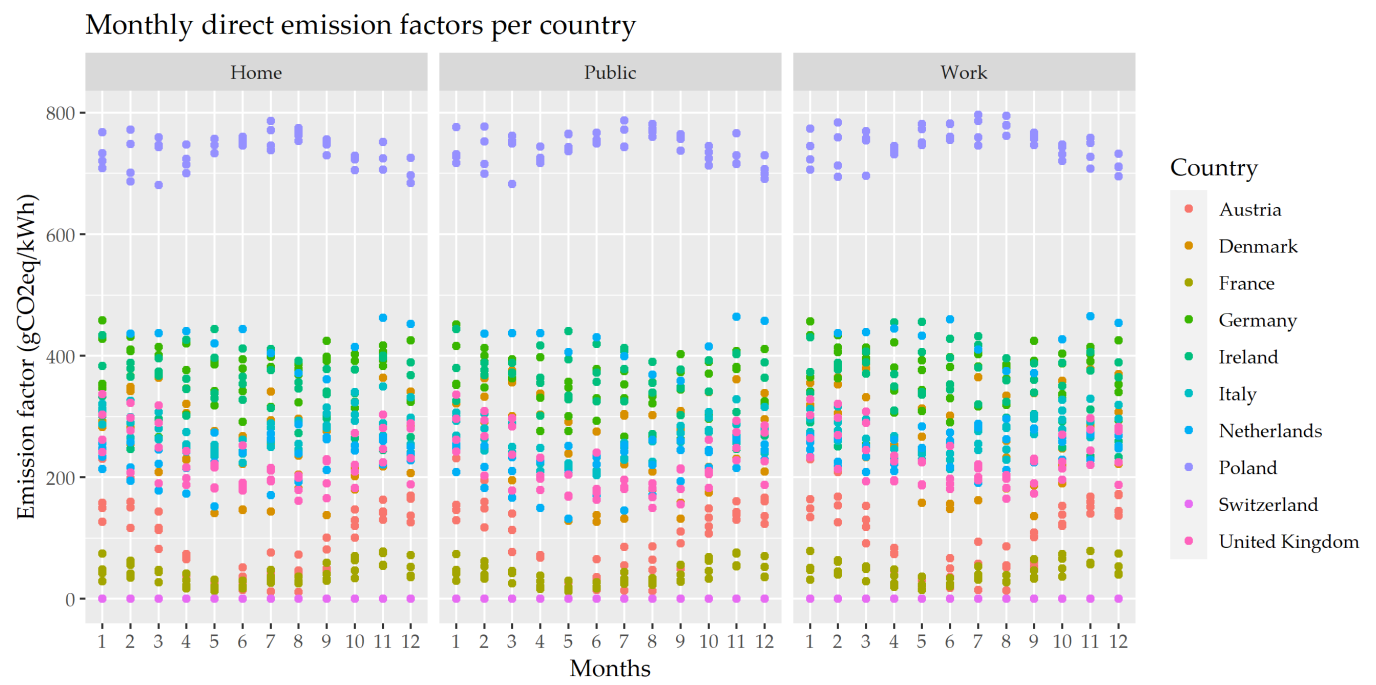

Figure 6. Monthly emission factors of EV charging in each country and each month.

\subsection{Variations in a Single Year}

To further evaluate the relative weight of annual variations and charging profiles in the variability of the annual emission factors, an analysis focusing on a single year can allow to highlight the effect of the latter aspect. For this reason, Figure 7 reports a comparison of emission factors for each profile considering the data of 2019, that were the most recent available. Moreover, given the issues of data quality discussed above, 2019 appeared to be less affected by these potential inaccuracies. However, it is important to note that the analysis on the other years resulted in very similar results.

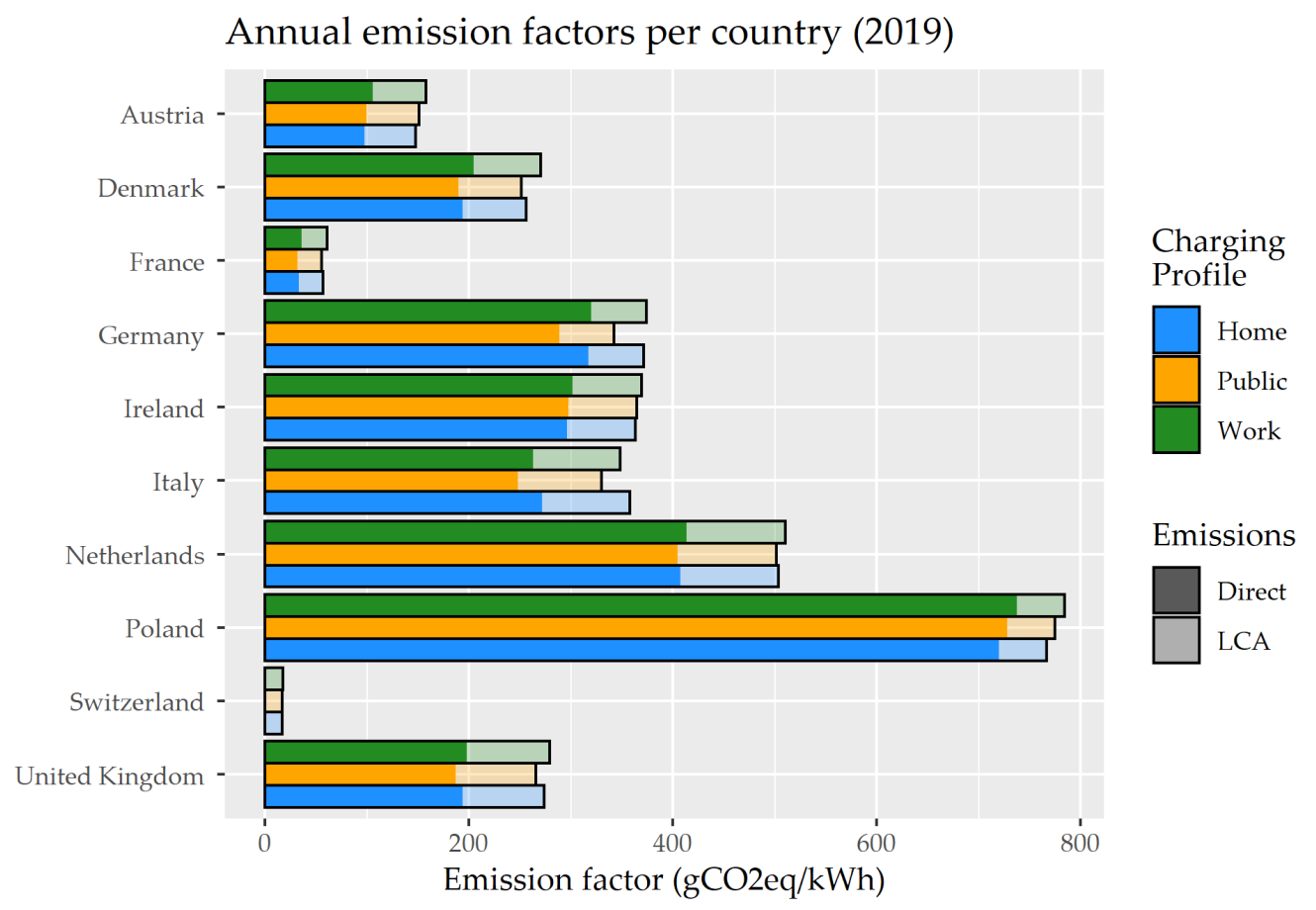

Figure 7. Annual emission factors of EV charging considering different profiles, year 2019.

The chart shows clearly that the emissions associated with the Work profile are higher in all the countries but Italy, for both direct emissions and LCA emissions. This charging profile is strongly concentrated in the beginning of the morning, when people arrive to their work location and plug-in their electric cars. In most countries the morning hours are already characterized by a peak of electricity 
consumption, which may require the operation of dispatchable fossil plants to guarantee the energy supply. For this reason, a better approach would be to develop strategies to distribute the peak demand over a higher number of hours, considering the fact that people will remain to work for large part of the day. However, it is important to underline that future conditions may vary, in particular with the possible implementation of electricity storage and other flexibility options. The charging profile with minimum impact varies from a country to another, with a slight majority of countries showing lower impacts for Public charging.

Moreover, when considering the range of variation of the different profiles against the mean value, we observe that it remains rather limited for any given country and year. With the exception of the Netherlands in 2016, which may also be affected by some low-quality data, all the other combinations of country and year show ranges of variation (calculated as the ratio between the difference of maximum and minimum values and the average value) lower than $10 \%$ (with an average value of $6 \%$ and a minimum value of $1 \%$ ). On the other hand, when considering the variations of the emission factor of each charging profile over the years for any given country, the ranges of variations are significantly higher. Excluding the values for the Netherlands, due to the potential issues with data quality for 2016, the average range of variation is $18 \%$, much higher than the $6 \%$ variation associated to the profiles.

Thus it is clear that, within the data considered in this study, the variation related to the year has a higher impact that the variation associated to the charging profiles. Given the fact that the three charging profiles that we have chosen are already representing very different behaviours, we expect that a sensitivity analysis would still confirm this limited variability, when evaluating aggregated profiles.

Another interesting result is that in most cases, the three different charging profiles result in higher annual emission factors in comparison with the mean emission factor for each country, calculated as a simple average of all the hourly values over the year. This result suggests that these charging profiles end up in slightly higher emissions than those that can be calculated by using simplified values, which would then underestimate these impacts. At the same time, the differences remain generally limited, suggesting that also quite different profiles may not lead to dramatic changes in the emissions associated to EVs charging.

On the top of that, it is useful to remind that the aggregated EV charging profile in any country is generally a mix of the different profiles that have been considered here, since users are generally relying on multiple EV charging solutions. As a result, the combined effect on the average EV charging profile in a country may be even more similar to the average value of the electricity mix for this country. Still, the information of the effectiveness of different profiles may remain an important insight for policy choices to support specific charging strategies.

These results suggest that under the current conditions the potential benefits of smart charging strategies based on emission savings may remain limited, although in future power systems characterized by higher shares of RES their role may prove to be very effective. Moreover, smart charging solutions are often designed to fulfill other benefits, such as avoiding excessive loads on the grid or provide flexibility services. Those aspects may thus represent a higher priority for the definition of proper charging profiles, given the limited variability of GHG emissions.

A final note is the fact that all the calculations in this work are performed with the current conditions of the electricity networks and generation mixes. The future will likely be characterized by an increase of the role of variable RESs, but at the same time the energy demand by EVs, in the case of large penetrations, may have a direct impact on the electricity dispatching and on the power mixes. In many countries these demand may remain marginal in comparison with other sectors, and it may also be compensated by energy efficiency measures in other applications, but further work may be required to assess the potential importance of this aspect.

\section{Conclusions}

This research work presents an analysis of the annual emission factor of different EV charging profiles by considering an hourly time step over one year. The analysis is performed on 10 different 
European countries and four years of operation, by comparing three alternative charging profiles that are representative of EV charging at home, at the work location and in public charging facilities.

The results show that in addition to the well-know variability between countries, which is related to the different mixes of electricity generation, there is an additional variability related to both the profiles and the years of operation. In particular, for some countries this latter effect appears to be more strong than for the charging profiles.

However, while there is generally an agreement on the importance of supporting smart charging strategies for EVs, the results of this study show that when assessing the effect of different charging profiles in a given country and a given year, the variability remains limited, with an average range of variation around $6 \%$. Thus, the difference of different charging strategies appears lower than expected. Still, other optimized profiles may provide better results, but they need to be specifically considered in each different case.

On the other hand, for any given country and charging profile, the variation of the year of analysis resulted in an average range of variation of $18 \%$, highlighting the significant variability in the electricity mix of these European countries over the years. This fact underlines the importance of considering multiple years when estimating the emissions related to the use of EVs in any given country, accounting for the potential uncertainty related to varying electricity mixes over the years.

The results of this study provide a preliminary assessment of the difference in GHG emissions associated to multiple EV charging profiles. The results of this work may be strengthened by considering a large amount of real EV profiles rather than the archetypal profiles considered in this work. This could provide additional insights on the variability across multiple changing strategies. Unfortunately, statistically significant datasets from real cases and from multiple countries are seldom available for research purposes. Additionally, an improvement of the time resolution going beyond the hourly data that have been used here could provide additional insights, especially when applied to fast-charging systems.

Author Contributions: Conceptualization, M.N. and F.N.; methodology, F.N. and M.N.; data curation, F.N. and M.N.; visualisation M.N.; writing—original draft preparation, F.N. and M.N.; writing—review and editing, F.N. and M.N. All authors have read and agreed to the published version of the manuscript.

Funding: This research received no external funding.

Conflicts of Interest: The authors declare no conflict of interest.

\section{Abbreviations}

The following abbreviations are used in this manuscript:

$\begin{array}{ll}\text { CHP } & \text { combined heat and power } \\ \text { EF } & \text { emissions factor } \\ \text { GHG } & \text { greenhouse gases } \\ \text { LCA } & \text { life cycle assessment } \\ \text { NGCC } & \text { natural gas combined cycle } \\ \text { PEF } & \text { primary energy factor } \\ \text { RES } & \text { renewable energy sources } \\ \text { TSO } & \text { transmission system operator }\end{array}$

\section{References}

1. International Energy Agency. World Energy Outlook 2018-Part B "Special Focus on Electricity"; International Energy Agency: Paris, France, 2018.

2. Bellocchi, S.; Klöckner, K.; Manno, M.; Noussan, M.; Vellini, M. On the role of electric vehicles towards low-carbon energy systems: Italy and Germany in comparison. Appl. Energy 2019, 255, 113848. [CrossRef]

3. Hansen, K.; Mathiesen, B.V.; Skov, I.R. Full energy system transition towards $100 \%$ renewable energy in Germany in 2050. Renew. Sustain. Energy Rev. 2019, 102, 1-13. [CrossRef] 
4. Guo, J.; Zhang, X.; Gu, F.; Zhang, H.; Fan, Y. Does air pollution stimulate electric vehicle sales? Empirical evidence from twenty major cities in China. J. Clean. Prod. 2020, 249, 119372. [CrossRef]

5. Clauß, J.; Stinner, S.; Solli, C.; Lindberg, K.B.; Madsen, H.; Georges, L. A generic methodology to evaluate hourly average $\mathrm{CO}$ 2eq. intensities of the electricity mix to deploy the energy flexibility potential of Norwegian buildings. In Proceedings of the 10th International Conference on System Simulation in Buildings, Liege, Belgium, 10-12 December 2018.

6. Noussan, M.; Tagliapietra, S. The effect of digitalization in the energy consumption of passenger transport: An analysis of future scenarios for Europe. J. Clean. Prod. 2020, 258, 120926. [CrossRef]

7. Alonso Raposo, M.; Ciuffo, B.; Alves Dies, P.; Ardente, F.; Aurambout, J.-P.; Baldini, G.; Baranzelli, C.; Blagoeva, D.; Bobba, S.; Braun, R.; et al. The Future of Road Transport-Implications of Automated, Connected, Low-Carbon and Shared Mobility. 2019. Available online: http://publications.jrc.ec.europa. eu/repository/bitstream/JRC116644/fr-future-road-transport-online.pdf (accessed on 15 April 2020). [CrossRef]

8. Alhelou, H.H.; Hayek, G. 9.4 Electric Vehicles Grid Integration. In Handbook of Research on Smart Power System Operation and Control; IGI Global: Hershey, PA, USA, 2019.

9. Bunsen, T.; Cazzola, P.; D'Amore, L.; Gorner, M.; Scheffer, S.; Schuitmaker, R.; Signollet, H.; Tattini, J.; Paoli, J.T.L. Global EV Outlook 2019 to Electric Mobility; OECD iea.org; IEA: Paris, France, 2019; p. 232.

10. Salvucci, R.; Petrović, S.; Karlsson, K.; Wråke, M.; Uteng, T.P.; Balyk, O. Energy Scenario Analysis for the Nordic Transport Sector: A Critical Review. Energies 2019, 12, 2232. [CrossRef]

11. Noussan, M.; Roberto, R.; Nastasi, B. Performance indicators of electricity generation at country level-The case of Italy. Energies 2018, 11, 650. [CrossRef]

12. Neirotti, F.; Noussan, M.; Simonetti, M. Towards the electrification of buildings heating-Real heat pumps electricity mixes based on high resolution operational profiles. Energy 2020, 195, 116974. [CrossRef]

13. Vuarnoz, D.; Jusselme, T. Temporal variations in the primary energy use and greenhouse gas emissions of electricity provided by the Swiss grid. Energy 2018, 161, 573-582. [CrossRef]

14. Mozafar, M.R.; Amini, M.H.; Moradi, M.H. Innovative appraisement of smart grid operation considering large-scale integration of electric vehicles enabling V2G and G2V systems. Electr. Power Syst. Res. 2018, 154, 245-256. [CrossRef]

15. Deilami, S.; Muyeen, S.M. An Insight into Practical Solutions for Electric Vehicle Charging in Smart Grid. Energies 2020, 13, 1545. [CrossRef]

16. Lee, Z.J.; Li, T.; Low, S.H. ACN-Data: Analysis and Applications of an Open EV Charging Dataset. In Proceedings of the Tenth International Conference on Future Energy Systems (e-Energy '19), Phoenix, AZ, USA, 25-28 June 2019.

17. Xydas, E.; Marmaras, C.; Cipcigan, L.M.; Jenkins, N.; Carroll, S.; Barker, M. A data-driven approach for characterising the charging demand of electric vehicles: A UK case study. Appl. Energy 2016, 162, 763-771. [CrossRef]

18. Brady, J.; O'Mahony, M. Modelling charging profiles of electric vehicles based on real-world electric vehicle charging data. Sustain. Cities Soc. 2016, 26, 203-216. [CrossRef]

19. Flammini, M.G.; Prettico, G.; Julea, A.; Fulli, G.; Mazza, A.; Chicco, G. Statistical characterisation of the real transaction data gathered from electric vehicle charging stations. Electr. Power Syst. Res. 2019, 166, $136-150$. [CrossRef]

20. Pan, Z.; Wang, J.; Liao, W.; Chen, H.; Yuan, D.; Zhu, W.; Fang, X.; Zhu, Z. Data-Driven EV Load Profiles Generation Using a Variational Auto-Encoder. Energies 2019, 12, 849. [CrossRef]

21. Schäuble, J.; Kaschub, T.; Ensslen, A.; Jochem, P.; Fichtner, W. Generating electric vehicle load profiles from empirical data of three EV fleets in Southwest Germany. J. Clean. Prod. 2017, 150, 253-266. [CrossRef]

22. Canizes, B.; Soares, J.; Costa, A.; Pinto, T.; Lezama, F.; Novais, P.; Vale, Z. Electric Vehicles' User Charging Behaviour Simulator for a Smart City. Energies 2019, 12, 1470. [CrossRef]

23. Heinz, D. Erstellung und Auswertung repräsentativer Mobilitäts- und Ladeprofile für Elektrofahrzeuge in Deutschland; Working Paper Series in Production and Energy; KIT: Karlsruhe, Germany, 2018; p. 30. [CrossRef]

24. European Network of Transmission System Operators for Electricity. Entsoe Website. Available online: https:/ / www.entsoe.eu/ (accessed on 15 April 2020). 
25. Entsoe. ENTSOE TSO. Available online: https://www.entsoe.eu/about/inside-entsoe/members/ (accessed on 5 April 2020).

26. European Commission. Clean Energy Package for all Europeans-Website. Available online: https://ec. europa.eu/energy/en/topics/energy-strategy-and-energy-union/clean-energy-all-europeans (accessed on 15 April 2020).

27. Entsoe. ENTSO-E Annual Report-2018. 2019. Available online: https://annualreport2018.entsoe.eu/ (accessed on 15 May 2020).

28. Hirth, L.; Mühlenpfordt, J.; Bulkeley, M. The ENTSO-E Transparency Platform-A review of Europe's most ambitious electricity data platform. Appl. Energy 2018, 225, 1054-1067. [CrossRef]

29. European Commission. A Review of the ENTSO-E Transparency Platform; European Commission: Brussels, Belgium, 2017; pp. 1-58.

30. Gotzens, F.; Heinrichs, H.; Hörsch, J.; Hofmann, F. Performing energy modelling exercises in a transparent way-The issue of data quality in power plant databases. Energy Strategy Rev. 2019, 23, 1-12. [CrossRef]

31. Schlömer , S.; Bruckner, T.; Fulton, L.; Hertwich, E.; McKinnon, A.; Perczyk, D.; Roy, J.; Schaeffer, R.; Sims, R.; Smith, P.; et al. Annex III: Technology-specific cost and performance parameters. In Climate Change 2014: Mitigation of Climate Change. Contribution of Working Group III to the Fifth Assessment Report of the Intergovernmental Panel on Climate Change; Cambridge University Press: Cambridge, UK; New York, NY, USA, 2014.

32. ISPRA. Fattori di Emissione di Produzione e Consumo di Elettricità-2019; ISPRA: Rome, Italy, 2019. (In Italian)

33. Noussan, M. Allocation factors in Combined Heat and Power systems-Comparison of different methods in real applications. Energy Convers. Manag. 2018, 173, 516-526. [CrossRef]

(C) 2020 by the authors. Licensee MDPI, Basel, Switzerland. This article is an open access article distributed under the terms and conditions of the Creative Commons Attribution (CC BY) license (http:/ / creativecommons.org/licenses/by/4.0/). 